\title{
Peramalan Dengan Model SVAR Pada Data Inflasi Indonesia Dan Nilai Tukar Rupiah Terhadap Dolar Amerika Dengan Menggunakan Metode Bootstrap
}

\author{
Daivi S. Wardani ${ }^{1}$, Adi Setiawan ${ }^{2}$, Didit B. Nugroho ${ }^{3}$
}

\begin{abstract}
${ }^{1}$ PS. Matematika, Fak. Sains dan Matematika, UKSW Salatiga, daivisintaw@yahoo.com
${ }^{2}$ PS. Matematika, Fak. Sains dan Matematika, UKSW Salatiga, adi setia 03@ yahoo.com

${ }^{3}$ PS. Matematika, Fak. dan Matematika, UKSW Salatiga, didit.budinugroho@ staff.uksw.edu
\end{abstract}

\begin{abstract}
Abstrak
Model Structural Vector Autoregression (SVAR) pada data inflasi Indonesia dan nilai tukar rupiah terhadap dolar Amerika telah dikaji dan dihasilkan estimasi untuk parameter model. Dalam studi ini, metode bootstrap diaplikasikan untuk mengestimasi parameter-parameter dari model. Metode bootstrap merupakan metode resampling dari data asli untuk mendapatkan data baru dengan banyak pengulangan yang terjadi. Dengan bantuan Software R i386 3.0.1, dari metode bootstrap diperoleh estimasi titik (median bootstrap) dan interval konfidensi bootstrap persentil yang mengandung hasil prediksi dengan metode klasik. Hasil peramalan menunjukkan bahwa, hasil darimetode langsung yang diperoleh dalam kajian sebelumnya lebih baik daripada dengan menggunakan metode bootstrap.
\end{abstract}

Kata kunci : Inflasi, Metode Bootstrap, Nilai Tukar Rupiah Terhadap USD, SVAR.

\section{SVAR Model Prediction on Indonesia Inflation Data and Rupiahs Exchange Rate of US Dollars by using Bootstrap Method}

\begin{abstract}
Structural Vector Autoregression Model (SVAR) has already used to estimate parameter on model of Indonesia's inflation data and the US dollar exchange rate to rupiah. In this study, the bootstrap method was applied to estimate the parameters of the model. Bootstrap methods is a resampling method based the original data to obtain new data with many replication with replacement. By using of Software $R$ i386 version 3.0.1, the point estimate can be obtained by the median bootstrap and bootstrap percentile confidence interval that containing the predicted results by classical methods. The results show that the forecasting by using the classical method is better than using the bootstrap method.
\end{abstract}

Keywords: Inflation, Bootstrap Methods, USD Exchange Rate, SVAR.

\section{Pendahuluan}

Peramalan dengan SVAR pada data inflasi dan nilai tukar rupiah terhadap USD telah didapatkan model pada lag 6 dengan bentuk [1]:

$B Y_{t}=\Gamma_{0}+\Gamma_{1} Y_{t-1}+\Gamma_{2} Y_{t-2}+\Gamma_{3} Y_{t-3}+\Gamma_{4} Y_{t-4}+\Gamma_{5} Y_{t-5}+\Gamma_{6} Y_{t-6}+\varepsilon_{t}$,
dimana $B=\left[\begin{array}{cc}1 & b_{12} \\ b_{21} & 1\end{array}\right], Y_{t}$ adalah vektor berukuran $n \times 1$ yang mengandung $n$ variabel dalam SVAR, $\Gamma_{0}$ adalah vektor berukuran $n \times 1$ yang berisikan intersep, $\Gamma_{1}, \Gamma_{2}, \ldots, \Gamma_{6}$ adalah matriks berukuran $n \times n$ yang berisikan parameter-parameter dalam SVAR, dan $\varepsilon_{t}$ adalah eror dari model SVAR. Parameter-parameter yang diperoleh dari model digunakan untuk meramalkan inflasi dan nilai tukar rupiah terhadap USD untuk periode kedepan. Pada penelitian ini parameter akan dibangkitkan berdasarkan metode bootstrap. Tujuan dari penelitian ini adalah memprediksi data inflasi dan nilai tukar rupiah terhadap USD dengan menerapkan metode bootstrap untuk memperoleh estimasi titik atau median bootstrap serta interval konfidensi bootstrap persentil sebagai hasil peramalan pada model SVAR. Peramalan sebelumnya (tanpa metode bootstrap) dan peramalan dengan menggunakan bootstrap akan dibandingkan untuk menentukan manakah peramalan yang memiliki kesalahan relatif lebih kecil sehingga prediksinya bisa dianggap lebih akurat. 


\section{Metode Bootstrap}

Metode Bootstrap merupakan suatu metode resampling atau pengambilan sampelsampel baru secara acak dengan pengembalian berdasarkan sampel asli sebanyak $L$ kali [2]. Dibuat interval konfidensi bootstrap persentil 95\% dari hasil pembentukan sampel baru oleh bootstrap. Kemudian dilakukan ulangan sejumlah bilangan besar $L$ kali pada sampel baru tersebut. Langkahlangkah dalam membuat interval konfidensi bootstrap persentil adalah melakukan proses bootstrap sebanyak bilangan besar $L$ kali, kemudian dengan memilih koefisien konfidensi $95 \%$ maka dapat ditentukan interval konfidensi $95 \%$ yaitu dengan memilih batas atas sebesar $97.5 \%$ dan batas bawah sebesar $2.5 \%$.

\section{Vector Autoregression (VAR)}

Pertama kali model VAR diperkenalkan oleh C.A. Sims (1972) sebagai pengembangan dari pemikiran Granger (1969) [3]. VAR menjelaskan bahwa setiap variabel yang ada dalam model tergantung pada pergerakan masa lalu variabel tersebut dan juga pergerakan masa lalu seluruh variabel yang ada dalam sistem [4]. Salah satu keunggulan dari model VAR adalah peneliti tidak perlu menentukan mana variabel endogen dan mana variabel eksogen karena semua variabel dalam VAR adalah endogen. Secara umum VAR orde $p$ dituliskan sebagai berikut :

$$
Y_{t}=A_{0}+A_{1} Y_{t-1}+A_{2} Y_{t-2}+\ldots+A_{p} Y_{t-p}+e_{t}
$$

dengan

$Y_{t}=$ vektor berukuran $n \times 1$ yang mengandung $n$ variabel dalam VAR,

$A_{0}=$ vektor berukuran $n \times 1$ yang berisikan intersep,

$A_{i}=$ matriks berukuran $n \times n$ yang berisikan koefisien-koefisien dalam VAR,

$e_{t}=$ vektor berukuran $n \times 1$ berisikan galat dari model VAR.

Model VAR yang digunakan akan dibentuk dalam tahapan pengujian pra-estimasi. Meliputi tahapan pengujian stasioneritas data dan penentuan lag optimal.

\section{Struktural Vektor Autoregresi (SVAR)}

SVAR merupakan pengembangan dari metode VAR. Metode estimasi SVAR digunakan untuk mendapatkan ortogonalisasi suku eror tak rekursif (non recursive error term) dalam kerangka analisis impulse respons. Untuk memperoleh ortogonalisasi suku eror tak rekursif tersebut, maka pada penelitian ini diterapkan beberapa batasan untuk mengidentifikasi komponen struktural dalam suku eror. Bentuk Struktural Vektor Autoregresi dengan lag $p$ memiliki model:

$$
B Y_{t}=\Gamma_{0}+\Gamma_{1} Y_{t-1}+\Gamma_{2} Y_{t-2}+\ldots+\Gamma_{p} Y_{t-p}+\varepsilon_{t}
$$

dengan

$B=\left[\begin{array}{cc}1 & b_{12} \\ b_{21} & 1\end{array}\right]$,

$Y_{t}=$ vektor berukuran $n \times 1$ yang mengandung $n$ variabel dalam SVAR,

$\Gamma_{0}=$ vektor berukuran $n \times 1$ yang berisikan intersep,

$\Gamma_{i}=$ matriks berukuran $n \times n$ yang berisikan koefisien-koefisien dalam SVAR,

$\varepsilon_{t}=$ white noise .

\section{Kesalahan Relatif}

Kesalahan relatif (relatif error) adalah ukuran kesalahan dalam kaitannya dengan pengukuran. Kesalahan relatif didefinisikan dengan:

$$
e_{r}=\left|\frac{X_{s}-X_{a}}{X_{s}}\right|
$$

dengan $e_{r}$ adalah kesalahan relatif, $X_{s}$ adalah nilai sebenarnya, $X_{a}$ adalah nilai perhitungan. 
Untuk mencari rata-rata kesalahan relatif yang terjadi pada suatu data dinyatakan dengan :

$$
\text { Rata-rata kesalahan relatif }=\frac{\sum \text { kesalahan relatif }}{n} .
$$

\section{Metode Penelitian}

Data yang digunakan adalah data inflasi yang diambil dari www.bps.go.id dan data nilai tukar rupiah terhadap USD yang diambil dari www.bi.go.id. Data yang digunakan adalah dari bulan Januari 2011 sampai dengan September 2014. Analisis data dengan menggunakan alat bantu program aplikasi R i386 3.0.1. Dalam penelitian ini akan dilakukan peramalan data inflasi dan nilai tukar rupiah terhadap USD pada model SVAR dengan menggunakan metode bootstrap untuk mengestimasi variabel $\Gamma_{i}$. Penggunaan bootstrap untuk mendapatkan estimasi titik atau median bootstrap dapat diringkas dalam langkah-langkah sebagai berikut:

1. Dimisalkan data asal $Y_{1}, Y_{2}, \ldots, Y_{n}$.

2. Berdasarkan pada data asal, dibentuk $A_{0}, A_{1}, \ldots, A_{p}$ dengan $p$ adalah lag yang terpilih.

3. Dihitung $e_{t}=Y_{t}-\hat{Y}_{t}=Y_{t}-A_{0}-A_{1} Y_{t-1}-\ldots-A_{p} Y_{t-p}$.

4. Sampel $e_{t}$ diambil dengan pengembalian sebanyak $n$ kali sehingga diperoleh $e_{t}^{*}$.

5. Dibentuk $Y_{t}^{*}=A_{0}+A_{1} Y_{t-1}+\ldots+A_{p} Y_{t-p}+e_{t}^{*}$

6. Berdasarkan $Y_{t}^{*}$ yang didapatkan maka dapat dihitung $A_{0}{ }^{*}, A_{1}^{*}, \ldots, A_{p}{ }^{*}$.

7. Prosedur $2-6$ diulang sebanyak $L$ kali dengan $L$ adalah bilangan besar, sehingga didapatkan :

$$
\begin{aligned}
& A_{0}^{*(1)}, A_{1}^{*(1)}, \ldots, A_{p}^{*(1)} \\
& A_{0}^{*(2)}, A_{1}^{*(2)}, \ldots, A_{p}^{*(2)} \\
& \ldots \\
& A_{0}^{*(L)}, A_{1}^{*(L)}, \ldots, A_{p}^{*(L)}
\end{aligned}
$$

8. Berdasarkan perolehan pada prosedur 7, selanjutnya akan dikali dengan $B$ dan diulang sebanyak $L$ kali, sehingga didapatkan:

$$
\begin{aligned}
& \Gamma_{0}^{*(1)}, \Gamma_{1}^{*(1)}, \ldots, \Gamma_{p}^{*(1)} \\
& \Gamma_{0}^{*(2)}, \Gamma_{1}^{*(2)}, \ldots, \Gamma_{p}^{*(2)} \\
& \ldots \\
& \Gamma_{0}^{*(L)}, \Gamma_{1}^{*(L)}, \ldots, \Gamma_{p}^{*(L)}
\end{aligned}
$$

\section{Profil Data}

Data inflasi dan nilai tukar rupiah terhadap USD dari bulan Januari 2011 sampai dengan September 2014 ditampilkan dalam Gambar 1. Dari grafik terlihat bahwa data inflasi berfluktasi di sekitar rata-rata yang dapat diartikan bahwa data asli inflasi sudah stasioner. Untuk data nilai tukar rupiah terhadap USD, menunjukkan bahwa data belum stasioner, sehingga perlu dilakukan uji stasioneritas untuk data nilai tukar rupiah terhadap USD.
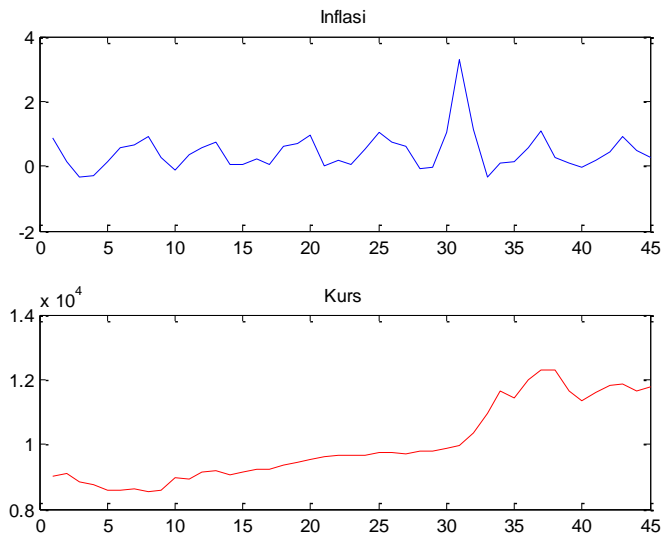

Gambar 1 : Data asli inflasi (atas) \&nilai tukar rupiah terhadap USD (bawah) 


\section{Hasil dan Pembahasan}

Pada [1] telah diperoleh parameter-parameter yaitu:

$$
\begin{aligned}
& \Gamma_{0}=\left[\begin{array}{l}
1.447 \\
-0.432
\end{array}\right], \quad \Gamma_{1}=\left[\begin{array}{cc}
-0.539 & 0.159 \\
1.263 & -0.086
\end{array}\right], \Gamma_{2}=\left[\begin{array}{cc}
-1.370 & 0.239 \\
0.281 & -0.185
\end{array}\right], \Gamma_{3}=\left[\begin{array}{cc}
-0.024 & 0.368 \\
0.025 & -0.427
\end{array}\right], \\
& \Gamma_{4}=\left[\begin{array}{ll}
-1.387 & 0.131 \\
1.212 & -0.093
\end{array}\right], \quad \Gamma_{5}=\left[\begin{array}{ll}
-0.570 & -0.101 \\
0.657 & -0.283
\end{array}\right] \quad \text { dan } \quad \Gamma_{6}=\left[\begin{array}{cc}
-0.018 & 0.367 \\
0.770 & -0.420
\end{array}\right] \text { sehingga }
\end{aligned}
$$

didapatkan model SVAR untuk lag 6 adalah :

$$
B Y_{t}=\Gamma_{0}+\Gamma_{1} Y_{t-1}+\Gamma_{2} Y_{t-2}+\Gamma_{3} Y_{t-3}+\Gamma_{4} Y_{t-4}+\Gamma_{5} Y_{t-5}+\Gamma_{6} Y_{t-6}+\varepsilon_{t} .
$$

\subsection{Metode bootstrap pada variabel $\Gamma_{i}$}

Dilakukan proses bootstrap pada variabel $\Gamma_{1}, \Gamma_{2}, \Gamma_{3}, \Gamma_{4}, \Gamma_{5}$ dan $\Gamma_{6}$. Proses bootstrap dilakukan dengan menyusun sampel baru dari data secara berpasangan dengan pengembalian. Data baru tersebut selanjutnya diramalkan untuk mendapatkan data inflasi dan nilai tukar rupiah terhadap USD pada 5 bulan kedepan. Hasil bootstrap yang digunakan diambil dari median data. Hasil estimasi median bootstrap dan estimasi interval konfidensi persentil pada parameter $\Gamma_{1}, \Gamma_{2}$, $\Gamma_{3}, \Gamma_{4}, \Gamma_{5}$ dan $\Gamma_{6}$ dapat dilihat pada Tabel 1.

Tabel 1 : Median bootstrap dan interval konfidensi bootstrap persentil

\begin{tabular}{|c|c|c|c|c|}
\hline & $\Gamma_{i}(1,1)$ & $\Gamma_{i}(1,2)$ & $\Gamma_{i}(2,1)$ & $\Gamma_{i}(2,2)$ \\
\hline \multirow{2}{*}{$\Gamma_{1}$} & -0.29 & 1.19 & 0.11 & -0.09 \\
\cline { 2 - 5 } & {$[-0.77,0.66]$} & {$[0.37,1.77]$} & {$[-0.24,0.42]$} & {$[-0.47,0.31]$} \\
\hline \multirow{2}{*}{$\Gamma_{2}$} & -1.09 & 0.36 & 0.16 & -0.18 \\
\cline { 2 - 5 } & {$[-1.67,-0.39]$} & {$[-0.43,1.21]$} & {$[-0.15,0.50]$} & {$[-0.56,0.16]$} \\
\hline \multirow{2}{*}{$\Gamma_{3}$} & -0.01 & 0.02 & 0.25 & -0.43 \\
\cline { 2 - 5 } & {$[-0.61,0.60]$} & {$[-0.74,0.80]$} & {$[-0.16,0.51]$} & {$[-0.72,-0.08]$} \\
\hline \multirow{2}{*}{$\Gamma_{4}$} & -0.99 & 1.21 & 0.09 & -0.09 \\
\cline { 2 - 5 }$\Gamma_{5}$ & {$[-1.65,0.19]$} & {$[0.54,1.92]$} & {$[-0.21,0.36]$} & {$[-0.44,0.27]$} \\
\cline { 2 - 5 } & -0.38 & 0.64 & -0.11 & -0.26 \\
\hline \multirow{2}{*}{$\Gamma_{6}$} & {$[-0.98,0.33]$} & {$[-0.18,1.38]$} & {$[-0.40,0.14]$} & {$[-0.63,0.13]$} \\
\cline { 2 - 5 } & 0.11 & 0.71 & 0.24 & -0.40 \\
\hline
\end{tabular}

Sebagai contoh hasil bootstrap untuk $\Gamma_{1}$ dibuat histogramnya dapat dilihat pada Gambar 2.

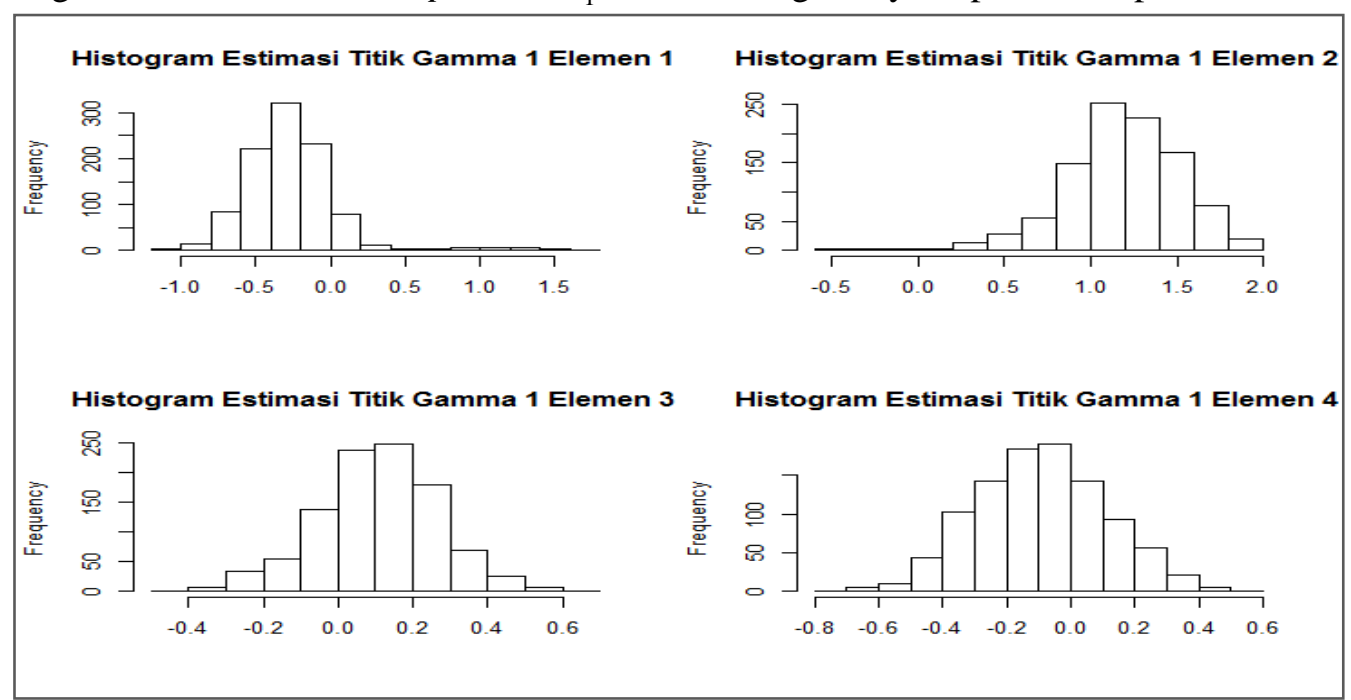

Gambar 2 : Histogram Estimasi Titik $\Gamma_{1}$ 


\subsection{Peramalan dengan model $S V A R$}

Model SVAR untuk mendapatkan peramalan yaitu :

$$
\begin{aligned}
Y_{t+1}{ }^{\prime} & =\Gamma_{0}+\Gamma_{1} Y_{t}+\Gamma_{2} Y_{t-1}+\Gamma_{3} Y_{t-2}+\Gamma_{4} Y_{t-3}+\Gamma_{5} Y_{t-4}+\Gamma_{6} Y_{t-5} \\
Y_{t+1}{ }^{\prime} & =B Y_{t+1} \\
Y_{t+1} & =B^{-1} Y_{t+1}^{\prime}
\end{aligned}
$$

Hasil peramalan data inflasi dan nilai tukar rupiah terhadap USD disajikan dalam Tabel 2.

Tabel 2 : Hasil peramalan inflasi dan nilai tukar rupiah terhadap USD (keluaran dari R)

\begin{tabular}{|c|c|c|c|c|}
\hline Bulan & Inflasi & $\begin{array}{c}\text { Inflasi } \\
\text { (hasil bootstrap) }\end{array}$ & $\begin{array}{c}\text { Nilai tukar rupiah } \\
\text { terhadap USD }\end{array}$ & $\begin{array}{c}\text { Nilai tukar rupiah terhadap } \\
\text { USD (hasil bootstrap) }\end{array}$ \\
\hline Okt-2014 & 0.07 & 0.060 & 0.75 & 0.760 \\
\hline Nov-2014 & -0.20 & -0.117 & -0.88 & -0.620 \\
\hline Des-2014 & 0.95 & 0.698 & 0.05 & -0.022 \\
\hline Jan-2015 & 0.67 & 0.756 & 1.31 & 0.873 \\
\hline Feb-2015 & 0.15 & 0.519 & -1.19 & -2.29 \\
\hline
\end{tabular}

Tabel 3 : Hasil peramalan inflasi dan data aslinya

\begin{tabular}{|c|c|c|c|}
\hline Bulan & Inflasi & Inflasi (hasil bootstrap) & Inflasi (data asli) \\
\hline Okt-2014 & 0.07 & 0.060 & 0.47 \\
\hline Nov-2014 & -0.20 & -0.117 & 1.50 \\
\hline Des-2014 & 0.95 & 0.698 & 2.46 \\
\hline Jan-2015 & 0.67 & 0.756 & - \\
\hline Feb-2015 & 0.15 & 0.519 & - \\
\hline
\end{tabular}

Tabel 4 : Hasil peramalan Nilai tukar rupiah terhadap USD (hasil transformasi) dan data aslinya

\begin{tabular}{|c|c|c|c|}
\hline Bulan & $\begin{array}{c}\text { Nilai tukar rupiah } \\
\text { terhadap USD }\end{array}$ & $\begin{array}{c}\text { Nilai tukar rupiah terhadap USD } \\
\text { (hasil bootstrap) }\end{array}$ & $\begin{array}{c}\text { Nilai tukar rupiah terhadap USD } \\
\text { (data asli) }\end{array}$ \\
\hline Okt-2014 & 11974.01 & 11976.76 & 12249 \\
\hline Nov-2014 & 11733.82 & 11806.99 & 12166 \\
\hline Des-2014 & 11747.34 & 11801.01 & 12325 \\
\hline Jan-2015 & 12107.08 & 12040.63 & - \\
\hline Feb-2015 & 11779.84 & 11422.18 & - \\
\hline
\end{tabular}

Akan dihitung kesalahan relatif pada data inflasi yaitu :

1. Bulan Oktober 2014.

$e_{r}=\left|\frac{0.47-0.07}{0.47}\right|=0.85$ (kesalahan relatif tanpa bootstrap)

$e_{r}=\left|\frac{0.47-0.060}{0.47}\right|=0.87$ (kesalahan relatif dengan bootstrap)

2. Bulan November 2014

$e_{r}=\left|\frac{1.50-(-0.20)}{1.50}\right|=1.13$ (kesalahan relatif tanpa bootstrap)

$e_{r}=\left|\frac{1.50-(-0.117)}{1.50}\right|=1.08$ (kesalahan relatif dengan bootstrap)

3. Bulan Desember 2014

$e_{r}=\left|\frac{2.46-0.95}{2.46}\right|=0.61$ (kesalahan relatif tanpa bootstrap) 


$$
e_{r}=\left|\frac{2.46-0.698}{2.46}\right|=0.72 \text { (kesalahan relatif dengan bootstrap) }
$$

sehingga diperoleh nilai rata-rata kesalahan relatifnya yaitu:

a. Rata-rata kesalahan relatif peramalan inflasi $=\frac{0.85+1.13+0.61}{3}=\frac{2.59}{3}=0.86$,

b. Rata-rata kesalahan relatif peramalan inflasi (setelah dilakukan bootstrap) $=\frac{0.87+1.08+0.72}{3}=\frac{2.67}{3}=0.89$.

Untuk menghitung kesalahan relatif pada data nilai tukar rupiah terhadap USD akan diberikan sebagai berikut :

1. Bulan Oktober 2014.

$$
\begin{aligned}
& e_{r}=\left|\frac{12249-11974.01}{12249}\right|=0.02 \text { (kesalahan relatif tanpa bootstrap) } \\
& e_{r}=\left|\frac{12249-11976.76}{12249}\right|=0.02 \text { (kesalahan relatif dengan bootstrap) }
\end{aligned}
$$

2. Bulan November 2014

$e_{r}=\left|\frac{12166-11733.82}{12166}\right|=0.03$ (kesalahan relatif tanpa bootstrap)

$e_{r}=\left|\frac{12166-1180699}{12166}\right|=0.03$ (kesalahan relatif dengan bootstrap)

3. Bulan Desember 2014

$e_{r}=\left|\frac{12325-11747.34}{12325}\right|=0.05$ (kesalahan relatif tanpa bootstrap)

$e_{r}=\left|\frac{12325-11801.01}{12325}\right|=0.04$ (kesalahan relatif dengan bootstrap)

Diperoleh nilai rata-rata kesalahan relatif yaitu:

a. Rata-rata kesalahan relatif peramalan nilai tukar rupiah terhadap USD

$$
=\frac{0.02+0.03+0.05}{3}=\frac{0.10}{3}=0.03,
$$

b. Rata-rata kesalahan relatif peramalan nilai tukar rupiah terhadap USD (setelah dilakukan bootstrap $)=\frac{0.02+0.03+0.04}{3}=\frac{0.09}{3}=0.03$.

Dari hasil perhitungan diperoleh nilai rata-rata kesalahan peramalan dengan model SVAR pada inflasi dan nilai tukar rupiah terhadap USD sebelum dilakukan bootstrap adalah 0.86 (86\%) dan $0.03(3 \%)$ dan nilai rata-rata kesalahan peramalan pada data yang sudah dilakukan bootstrap yaitu $0.89(89 \%)$ untuk Inflasi dan 0.03 (3\%) untuk nilai tukar rupiah terhadap USD.
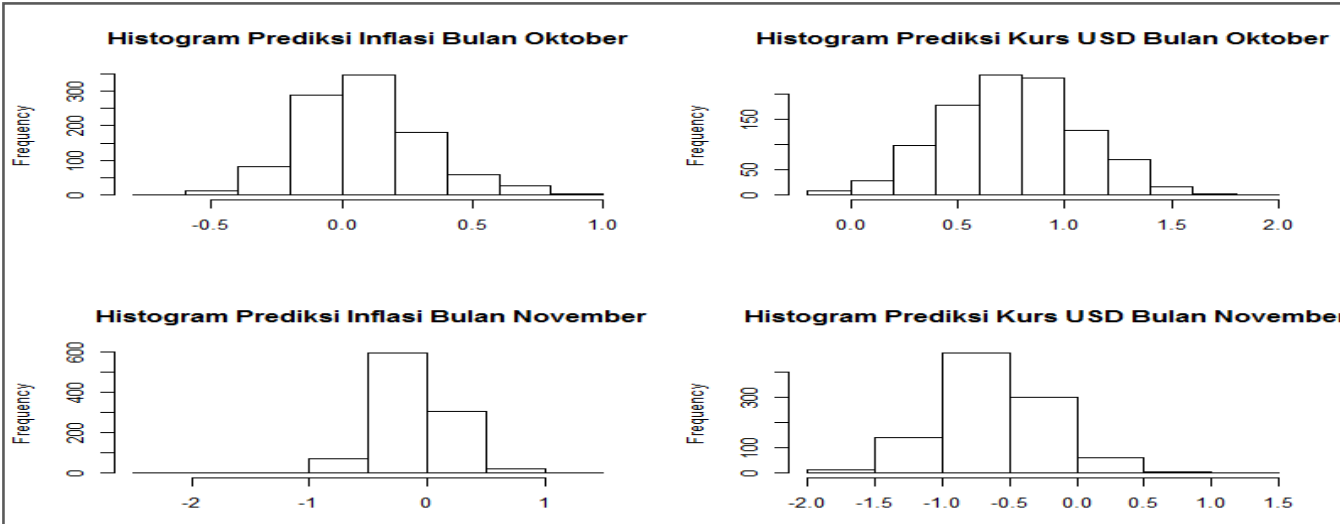

Gambar 3 : Histogram prediksi inflasi dan nilai tukar rupiah terhadap USD dengan model SVAR 
Kemudian dalam proses bootstrap untuk menentukan estimasi titik interval yang merupakan interval konfidensi bootstrap persentil 95\% pada sampel baru dengan pengulangan 1000 kali. Diperoleh hasil median bootstrap dan interval konfidensi bootstrap persentil yang disajikan pada Tabel 5.

Tabel 5 : Titik estimasi dan interval konfidensi peramalan data inflasi dan nilai tukar rupiah terhadap USD

\begin{tabular}{|c|c|c|}
\hline Bulan & Inflasi & Nilai tukar rupiah terhadap USD \\
\hline \multirow{2}{*}{ Oktober 2014 } & 0.06 & 0.76 \\
\cline { 2 - 3 } & {$[-0.34,0.63]$} & {$[0.13,1.36]$} \\
\hline \multirow{2}{*}{ November 2014 } & -0.12 & -0.62 \\
\cline { 2 - 3 } & {$[-0.65,0.51]$} & {$[-1.41,0.16]$} \\
\hline \multirow{2}{*}{ Desember 2014 } & 0.69 & -0.02 \\
\cline { 2 - 3 } & {$[0.16,1.39]$} & {$[-1.15,0.86]$} \\
\hline \multirow{2}{*}{ Januari 2015 } & 0.75 & 0.87 \\
\hline \multirow{2}{*}{ Februari 2015 } & {$[0.13,1.51]$} & $-0.15,2.42]$ \\
\cline { 2 - 3 } & 0.52 & {$[-2.29,1.83]$} \\
\hline
\end{tabular}

\section{Kesimpulan}

Berdasarkan hasil dan bahasan di bagian sebelumnya diperoleh bahwa hasil peramalan berdasarkan data inflasi di Indonesia dan nilai tukar rupiah terhadap USD tanpa melakukan bootstrap lebih baik dari pada menggunakan metode bootstrap. Hal ini dapat dilihat dari rata-rata kesalahan relatif tanpa bootstrap untuk inflasi sebesar $86 \%$ dan nilai tukar rupiah terhadap USD sebesar 3\%, lebih kecil dari pada rata-rata kesalahan relatif dengan metode bootstrap yaitu 89\% untuk inflasi dan 3\% untuk nilai tukar rupiah terhadap USD. Lebih lanjut perlu diselidiki kenapa kesalahan relatif data inflasi dari hasil penghitungan kedua metode sangat besar yaitu mendekati $100 \%$.

\section{Daftar Pustaka}

[1] Wardani, D. S., Setiawan.A, Nugroho, D.B. (2014). Peramalan Dengan Model SVAR Pada Data Inflasi Indonesia Dan Nilai Tukar Rupiah Terhadap Kurs Dolar Amerika, Prosiding Seminar Nasional Sains dan Pendidikan Sains, 4(1), UMP, Purworejo.

[2] Agustius, Y., dkk. (2013). Penerapan Metode Bootstrap Pada Uji Komparatif Non Parametrik 2 Sampel Studi Kasus: Inflasi Di Kota Purwokerto, Surakarta, Semarang, Dan Tegal Tahun 2003-2012.Prosiding Seminar Nasional Penelitian, Pendidikan dan Penerapan MIPA,FMIPA UNY,Yogyakarta.

[3] Hadiyatullah.(2011). Model Vector Autoregressive (VAR) dan Penerapannya untuk Analisis Pengaruh Harga Migas yerhadap Indeks Harga Konsumen (IHK) (Studi Kasus Daerah Istimewa Yogyakarta, Periode 1997-2009). FMIPA UNY, Yogyakarta.

[4] Novita, M.( 2009). Studi Kausalitas Granger Antara Nilai Tukar Rupiah Terhadap USD dan AUD Menggunakan Analisis VAR, FSM UKSW, Salatiga. 